\title{
Modelling Web-Based Instructional Systems
}

\section{Symeon Retalis \\ Department of Computer Science, University of Cyprus Nicosia, Cyprus}

\author{
Paris Avgeriou \\ Department of Electrical and Computer \\ Engineering, \\ National Technical University of Athens \\ Athens, Greece
}

retal@softlab_ntua.gr

\section{Executive Summary}

The size and complexity of modern instructional systems, which are based on the World Wide Web, bring about great intricacy in their crafting, as there is not enough knowledge or experience in this field. This imposes the use of new instructional design models in order to achieve risk-mitigation, cost and time efficiency, high pedagogical quality of the end product, which will capitalise on the potential of the networked technologies. This paper presents a model for constructing such systems, using a problemsolving approach that defines the solution of an instructional problem in both a pedagogical and a technical manner in a holistic view. This model tries to standardise the development of such systems supporting reusability at the design as well as the implementation level.

The pedagogical or non-technical solution is comprised of five interconnected sets of learning elements: the learning objectives, the didactic events, the syllabus, the assessment procedure and other issues like prerequisites, fees, technical constraints, etc. This first form of the solution is then transformed into a technical form that contains implementation sub-systems: the human subsystem, the learning resources subsystem, and the technical infrastructure subsystem. These subsystems are perceived as independent, autonomous entities that interact with each other through critical interfaces in a holistic fashion. The technical solution is therefore the system architecture of the web-based instructional system, which is engineered to satisfy the requirements specified by the pedagogical solution.

The proposed model has been empirically derived from actual web-based instructional systems, supporting undergraduate and postgraduate courses in the Computer Science discipline. One of these courses is presented in this paper, serving as a case study, and exhibiting the formulation of both types of the solution. Furthermore, in order to evaluate the effectiveness of the Web-based instructional systems, constructed with the proposed model, a summative evaluation method is employed that makes use of pre-test and post-test questionnaires. This evaluation method is briefly presented, together with a summary of its results on the case study course.

Material published as part of this journal, either on-line or in print, is copyrighted by the publisher of the Journal of Information Technology Education. Permission to make digital or paper copy of part or all of these works for personal or classroom use is granted without fee provided that the copies are not made or distributed for profit or commercial advantage AND that copies 1) bear this notice in full and 2) give the full citation on the first page. It is permissible to abstract these works so long as credit is given. To copy in all other cases or to republish or to post on a server or to redistribute to lists requires specific permission and payment of a fee. Contact Editor@JITE.org to request redistribution permission.
Finally the proposed model is examined in the context of current standardization efforts in the field of Learning Technology Systems.

Specifically it is demonstrated how the model can conform to the Learning Technology System Architecture draft standard of IEEE Learning Technology Standards Committee.

In conclusion, the model has shown encouraging results in the four systems it has been applied to. We mean to further elaborate on the model by employing it, to construct more instructional 
systems. We also aim in coding design experience in the field, in the well-established form of design patterns.

Keywords: Web-based Instructional Systems, Learning Technology Systems, model, e-learning, instructional design, evaluation, Learning Technology Standards.

\section{Introduction}

Instructional systems aim to support and partially automate the instructional process on a subject field, which might concern, for example, a course, a seminar or even a series of lectures (Gagné et al., 1984). From a different perspective, these systems intend to satisfy certain instructional needs for a subject domain, which have surfaced mainly because of the advances in research and technology, the emergence of the information society and the globalisation of markets (Hodgson, 1997).

Nowadays, instructional systems make extensive use of network technologies, especially the Internet and the World Wide Web, because of their potential, in advancing interactivity between learners and tutors, in offering flexibility concerning the way of learning, and in providing easy, one-stop maintenance and reusability of resources (McCormack \& Jones, 1997, Lowe \& Hall 1999). This trend entails the construction of complex instructional systems, i.e. the Web-based Instructional Systems (WbIS), that incorporate a variety of organisational, administrative, instructional, and technological components (Moore \& Kearsley, 1996, Carlson, 1998). The pursuance of quality in such complex systems is of paramount importance, although building high quality WbIS within specific time and fund limits is definitely quite a challenging task. There is no standard process to achieve this goal but the most promising approach seems to be the adoption, on behalf of the instructional designers, of a design and development model so as to reap several benefits (Tennyson \& Breuer, 1997), such as:

- To mitigate risks and improve the possibility of concluding the development process on schedule and within the estimated budget.

- To assure that the quality of the development process per se and the quality of the end product is guaranteed.

- To standardise the construction of new systems and consequently maintain and upgrade them more easily than ad hoc developments.

- To put emphasis on reusing parts of previously developed compliant systems, on a design or implementation level, thus reducing the development time and costs.

This paper describes a way of modelling web-based instructional systems and portrays the realization of this model into practice by showing a complete case study. The underlying idea of modelling web-based instructional systems is an explicit division of the instructional system under development into specific subsystems. Each one of these subsystems elucidates on how: a) the human agents (learners, teachers, tutors, administrators), b) the web-based learning resources, c) the other learning resources (e.g. material in printed or other analogue format), and d) the technological infrastructure, should accordingly participate in the instructional process. It is emphasized that the proposed model focuses on WbISs from an Information Technology perspective and does not represent current theories of learning.

This work accords with the philosophy of the IEEE Learning Technology Standards Committee (http://Itsc.1eee.org, the CEN/ISSS Learning Technology Workshop (http://wWw.cenorm.be/1sss/workshop/lt), the PROMETEUS Special Interest Group on the Design of Electronic Learning Environments hhttp://www.igd.fhg.de/ lindner/PROMETEUS/SIGDESIGN/Mission.htm, and the work on Educational Modelling Language (EML) (http://eml.ou.nl). AII these are major players in the development of technical standards, recommended practices, tools, 
and design methods that facilitate the development, deployment, maintenance and interoperation of computer implementations of education and training components and systems.

The structure of this paper is as follows: Section 2 will analyse the model and its philosophy while section 3 will show the realization of the model in practice. Several web-based systems have been developed with the aid of the proposed model, in an effort to enrich/enhance the traditional classroombased teaching process. One of these WbISs will be presented as a case study. Section 4 will present the current standardization efforts in designing learning technology systems and how the proposed model conforms to the most elaborated and stable of the existing standards, the IEEE LTSC LTSA. Section 5 will propose a method for summative evaluation of WbISs, which is based on the modelling philosophy aforementioned. This systematic method allows the evaluation of the learning impact of the WbIS subsystems, as well as the WbIS as a whole in great detail (in quantitative and qualitative terms). Some of the qualitative results from the method's application to the case study presented in section 3 will also be presented. Finally section 6 will wrap up with conclusions and ideas for future work.

\section{Analysis of the Model}

Instructional systems are constructed to solve specific instructional problems. In effect, the development process for WbISs should follow the principles of a problem-solving approach. This approach unfortunately cannot be generalized and automated, since each instructional development project is unique. In effect, it requires both the methodological solution and the development process to be based solely upon the given needs and requirements (Spector \& Song, 1995). In order to come up with the best solution, the instructional design group initially needs to make a description in non-technical terms of a solution to the given problem (which stems from instructional needs) as precisely as possible. At first, the instructional problem solution should not entail technicalities on how it will be implemented, but it should contain possible technical or ergonomic constraints, so as to leave space for several design and implementation options.

\section{Non-technical Solution}

The definition of the "non-technical" solution to an instructional problem can be generated by blending five interrelated sets of learning elements: the learning objectives, the didactic events, the syllabus, the assessment procedure and other issues like prerequisites, fees, technical constraints, etc. Having this formulated description as an input, which is graphically illustrated in Figure 1, the instructional designer should proceed in creating the architectural blueprint of the WbIS that will constitute a realisation of such a solution. Thus, such a"non-technical" solution, that is the instructional problem abstract solution, plays the role of requirements specification for the WbIS under construction.

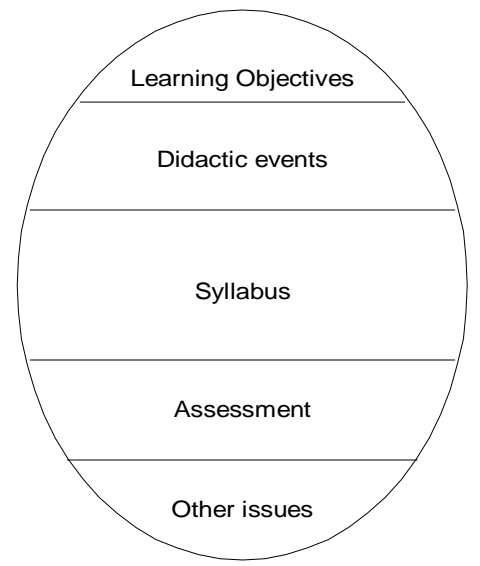

Figure 1. The formulated description of an instructional problem 


\section{Technical Solution}

Consequently the design process of a WbIS transforms the "non-technical" solution of the instructional problem into a technical solution. The architectural blueprint of an instructional system includes descriptions about four interrelated subsystems, as shown in Figure 2 below:

- The human subsystem, which describes the roles, in as much detail as possible, for each kind of human agent involved in the instructional process (Lindner, 2001).

- The web-based learning resources subsystem, which is perceived as a mosaic of online learning resources. Such learning resources can be course notes, slideware, study guides, self-assessment questionnaires, communication archives, learning material used for communication purposes, etc.

- The non web-based learning resources subsystem, like textbooks, papers, audio/video cassettes, CDs, DVDs, etc.

- The technical infrastructure subsystem, which is divided into common and special. An instructional system basically makes use of services from common infrastructure, which is a set of learning places, that support student learning in general (e.g. laboratories, networking facilities, etc.). However, in order to best support the instructional process, special infrastructure should be created (e.g. multimedia conferencing systems, state of the art hardware components, a specific learning management system, etc.), which will provide services unique to a particular instructional problem (Ford et al., 1996).

The process of creating the architectural blueprint is shown in Figure 2. It should be noted that according to the holistic theory (Humphrey, 1995), each subsystem should be itself an independent, viable system. In effect, this system model emphasizes on the decomposition of the whole instructional system into the subsystems, the relations among those subsystems, and the behavior of them as individual entities.

When breaking up a WbIS into sub-systems we need to keep the entirety in mind, as well as the interrelations of the sub-systems, otherwise reductionism might distort our understanding of the overall. For example, in order to facilitate communication among the human agents, special infrastructure in the means of synchronous and asynchronous communication tools might be purchased, special discussion topics should appear and the necessary training of the participants on the use of the infrastructure as well as on the techniques for effective collaboration should happen (McConnell, 1994). In case students prefer the sensing mode of perceiving rather than the intuitive mode, the learning resources could incorporate learning activities that will enable them to acquire concrete experiences as well as to navigate through the content via high degrees of structure.

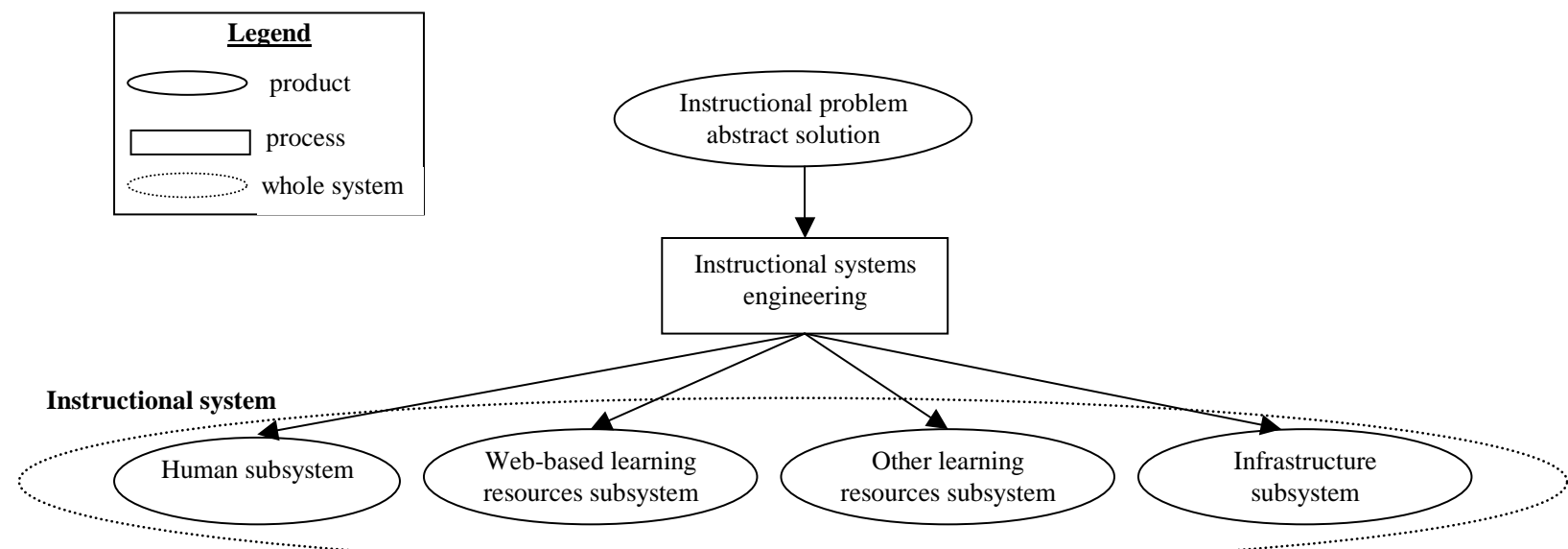

Figure 2. The process of creating an instructional system's architectural blueprint 
A WbIS must be developed through an evolution rather than a revolution (Schash, 1990), meaning that it is not released in one «big bang» at the end of the project. Rather, it can be developed as a series of fully functional builds (working versions of a WbIS). A build satisfies the current set of the requirements of the product under development. The underlying essence of the evolutionary development is that the client's perception (either learner's or teacher's or institutional organisation's) of the complete endproduct is a "moving target". While the builds are tested and summatively evaluated, the user's opinion regarding the characteristics of the system might change, resulting in changing the requirements and consequently the design and development of the future builds.

For example, the evaluation study for the first version of the WbIS on "Web Engineering", that will be presented in the next section showed that the students did not much appreciate the fact that:

- The elaborated case studies on the hypermedia development methodologies were limited.

- There were not many subjects for discussions.

- Some answers to students' queries were given personally without update to the discussion list.

Thus new version of this WbIS differed from the first version in the following points:

1. The subject matter experts provided some interesting discussion topics. The instructor and the tutors were better trained to moderate the discussion on these topics as well as to encourage and motivate students in participating to the discussions.

2. The web-based learning material was enriched by three detailed case studies on the use of hypermedia development methodologies.

3. The asynchronous discussion forum, which is incorporated into the WebCT, has been customised (i.e. by creating specific discussion fora) in order to facilitate the transfer of tutors' know-how to all students in a more structured way.

4. An on-line library with links to special and modern topics on Web Engineering was created.

\section{A Case Study}

The proposed model is the outcome of a combination of evolved practice with applied theory. Three instructional systems have been developed, following it closely, as yet. The subject domains of these systems are: 'Software Engineering', 'Introduction to Compilers', and 'Web Engineering'. The main objective of these WbISs was the modernization of the conventional curriculum and instructional delivery mode of undergraduate and postgraduate courses with the introduction of open learning delivery vehicles supplementary to the traditional ex-cathedra methods.

In this section, we present a brief description and analysis of the development of a web-based instructional system (WbIS) for supporting the learning process in the subject matter of "Web Engineering". The instructional problem for this course was to find effective ways to allow students to acquire technical skills on Internet programming as well as to give emphasis on specific development methods for web applications. The formulated abstract solution of this instructional problem should incorporate five items, as previously shown in Figure 1.

\section{Learning Outcomes}

Robert Gagné (1985) classified the types of learning outcomes as follows:

- intellectual skills

- concepts which are demonstrated by labelling or classifying things,

○ rules that are applied and principles that are demonstrated, 
○ problem solving that allows generating solutions or procedures,

- cognitive strategies which are used for learning,

- verbal information that is stated,

- motor skills which enable physical performance,

- attitudes that are demonstrated by preferring options.

Motor skills were not an appropriate learning outcome for this course. However, this course intends to offer students the rest of the learning outcomes. In general, the aim of the course is to augment students' knowledge and skills of technical nature, i.e. to enhance students' Internet and Web programming skills, as well as to provide a theoretical background on the design and development of web-based applications. In fact, the main emphasis has been put on persuading students to alter their modus operandi when creating a web-based application in order for them to follow suitable engineering methodologies. After the successful completion of this course, the students are better able to:

- follow systematic methodologies for web-based application development

- construct interactive, aesthetically attractive and user-friendly Web applications

- $\quad$ state practical web publishing problems and give examples of well designed web applications

\section{Didactic Events}

For this course eight of Gagné's Didactic Events (Gagné et al., 1984) have been considered as appropriate:

- Gaining attention - To ensure reception of coming instruction we give the learner a stimulus.

- Tell learners the learning objective - Tell the learner what they will be able to do because of the instruction.

- $\quad$ Stimulating recall of prior learning - Ask for recall of existing relevant knowledge.

- Presenting the stimulus - Display the content.

- Providing learning guidance - Help understanding (semantic encoding) by providing organization and relevance.

- Providing feedback - Give informative feedback on the learner's performance.

- Assessing performance - Require more learner performance, and give feedback, to reinforce learning.

- Enhancing retention and transfer to other contexts - Provide varied practice to generalise the capability.

The only didactic event that was decided not to be included was: "Eliciting performance". The students were not asked to respond to specific questions-tests for demonstrating learning.

\section{Syllabus}

The syllabus covers the following topics:

- An introduction to web publishing and programming techniques (both server-side and client-side programming, e.g. HTML, DHTML, XML, CGI, Javascript, Java applets \& servlets, ASP and JSP, web server installation and customisation, etc.) 
- Hypermedia design and development methodologies such as OOHDM (Schwabe \& Rossi 1995), RMM (Isakowitz 1995)

- Development methodologies for specific type of web applications such as web-based courseware, ecommerce applications

- Ergonomics of web-based applications

- Asynchronous and synchronous multimedia conferencing systems

- Examples of industrial web applications such as one for the Greek stock market, for a digital library and others

\section{Assessment}

The assessment for this course is based on students' performance on team projects. The students form small groups in order to construct web-based applications following specific methodologies. There is a variety of applications proposed to the students as subjects for their projects, such as the development of web sites for a laboratory, company, etc. or e-commerce sites or web-based instructional systems. The students are obliged to follow the development methodologies that are being taught during the lectures. The submission of intermediate deliverables and documentation is required on specific deadlines.

\section{Other Issues}

The audience of this course is postgraduate students (PhD students highly competent in computer skills). The majority have demanding research, development and tutoring obligations during their studies. Thus, it is a necessity to create a flexible learning environment. Moreover, a constraint imposed by the educational institute that hosted this course was that the open and distance learning methods should only be used complementary to the traditional ones, such as ex-cathedra lectures, peer tutorials, etc.

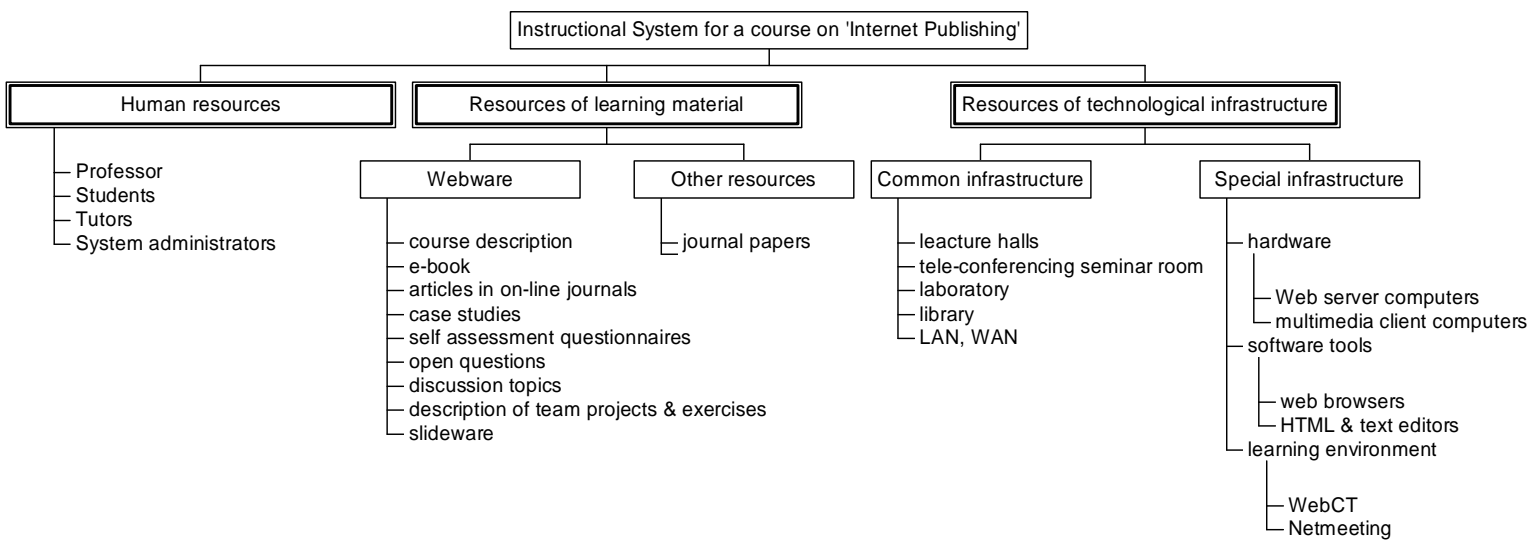

Figure 3: The structure of the WbIS on Web Engineering

Having formulated the abstract solution of the instructional problem in the aforementioned way, our instructional design decision was to deliver this course in a hybrid mode, in the sense that: a) few lectures on specialized topics are given at lecture halls, b) few live lectures are given by distance using the facilities of a tele-conferencing seminar room, c) face-to-face tutorials are given when needed and d) asynchronous and synchronous guidance is provided via e-mail, discussion forums, on-line chat and tele-conferencing systems. The WbIS' structure is shown in Figure 3.

\section{The Human Subsystem}

The human agents and their roles in this course are shown in Table 1: 


\begin{tabular}{|c|c|}
\hline Human agent & Roles \\
\hline Learner & $\begin{array}{l}\text { - Attends Lectures } \\
\text { - Navigates freely within the learning resources } \\
\text { - Explores information resources } \\
\text { - Asks questions } \\
\text { - Collaborates with other classmates in team } \\
\text { - } \text { projects } \\
\text { - } \text { Interacts with other learners either face-to-face } \\
\text { or via e-mail }\end{array}$ \\
\hline Instructor/tutor & $\begin{array}{l}\text { - Organises content into learning resources } \\
\text { - Gives lectures either face-to-face or by } \\
\text { distance } \\
\text { - Displays and updates information about the } \\
\text { course } \\
\text { - Brings up discussion topics } \\
\text { - Provides corrective feedback (either face-to- } \\
\text { - face or computer mediated e.g. via e-mail) } \\
\text { - Advises and tutors students } \\
\text { - } \text { Assesses the students } \\
\text { - Creates and manages project teams }\end{array}$ \\
\hline System Administrator & $\begin{array}{l}\text { - Administrates the technical infrastructure } \\
\text { - Administrates users' data } \\
\text { - Provides technical assistance }\end{array}$ \\
\hline
\end{tabular}

Table 1. Human agents' roles

This hybrid/enriched way of teaching was designed to be learner-centred; the roles of the human agents of the system were based on the cognitive theories of instruction that emphasise the active exploration, construction and problem solving activities. The learners are expected to seek and choose from available information at their own pace, according to their own needs, and preferences and the instructor is merely a facilitator and a guide to the learning process.

\section{The Learning Resources Subsystems}

The learning material for this course consisted of:

- web-based learning resources (webware)

- E-book (electronic book) in the form of hypermedia course notes. Its structure follows the UK's Open University standards for structuring the learning material into blocks and units.

- Slideware

- Descriptions of the course and the team projects.

- Case studies of team projects from past years

- Discussion topics

- On-line journal papers

- Self-assessment exercises 
- other learning resources

- journal papers

\section{Technological Infrastructure}

The cornerstone of the special technological infrastructure subsystem was the WebCT learning environment http://www.webct.com. This environment hosted the web-based learning resources (webware), the details about students and instructors (personal data and records), and the data used for administration (course management). In addition it provided asynchronous communication facilities (asynchronous discussion fora and e-mail). Microsoft Netmeeting was used for synchronous teleconferencing. An ordinary WWW browser (like Netscape Navigator, Internet Explorer) was adequate to browse through the material of the learning resources. The students could access the material either from the computers of a university laboratory or from their home or work provided that they had access to the Internet. Finally, for the purposes of their project assignments the students should also use the university library facilities or digital libraries. This plethora of learning places has demonstrated the effectiveness of the proposed model in alleviating the place and time constraints of learning.

All the above components of the course on Web Engineering are depicted within an object model in Figure 4. This object model uses the syntax and semantics of the object-oriented graphical modelling language Unified Modelling Language (UML) (http://www.rational.com/uml). The human resources have been modelled as classes of the 'actor' stereotype, which according to the UML is an entity that uses the system, in our case the WbIS.

The web-based instructional systems for the other two courses that were designed using the same model, differed from the aforementioned case study basically in the web-based learning resources subsystem. The course on Compilers contained a lot of self-assessment exercises while the course on Software Engineering involved material from some case studies that aided students to accomplish their team projects.

\section{The WbIS Model in the Context of Learning Technology Systems}

In order to comprehend the real nature of the proposed WbIS model, we need to put it into perspective, by examining it in the context of the family of systems it belongs to, namely the Learning Technology Systems (LTS). LTSs are learning, education and training systems that are supported by the Information Technology (IEEE LTSC 2001). Examples of such systems are computer-based training systems, intelligent tutoring systems, web-based distance learning systems and so on.

\section{Current Standardization Efforts}

The model proposed in this paper is fundamentally an architecture for WbISs, which are a specific kind of LTSs. The largest effort on developing an LTS architecture standard has been carried out in the IEEE P1484.1 Learning Technology Systems Architecture (LTSA) http://ltsc.1eee.org/wgI//ndex.html, which is a tentative and rather stable working standard. The LFSA deals with the Learning Technology System as a whole, encompassing a software system, human resources, other non-software resources, technical infrastructure and their interactions, just like the proposed model. The LTSA describes highlevel system architecture and layering for learning technology systems, and identifies the objectives of human activities and computer processes and their involved categories of knowledge. These are all encompassed into 5 layers, where each layer is a refinement of the concepts in the above layer. 


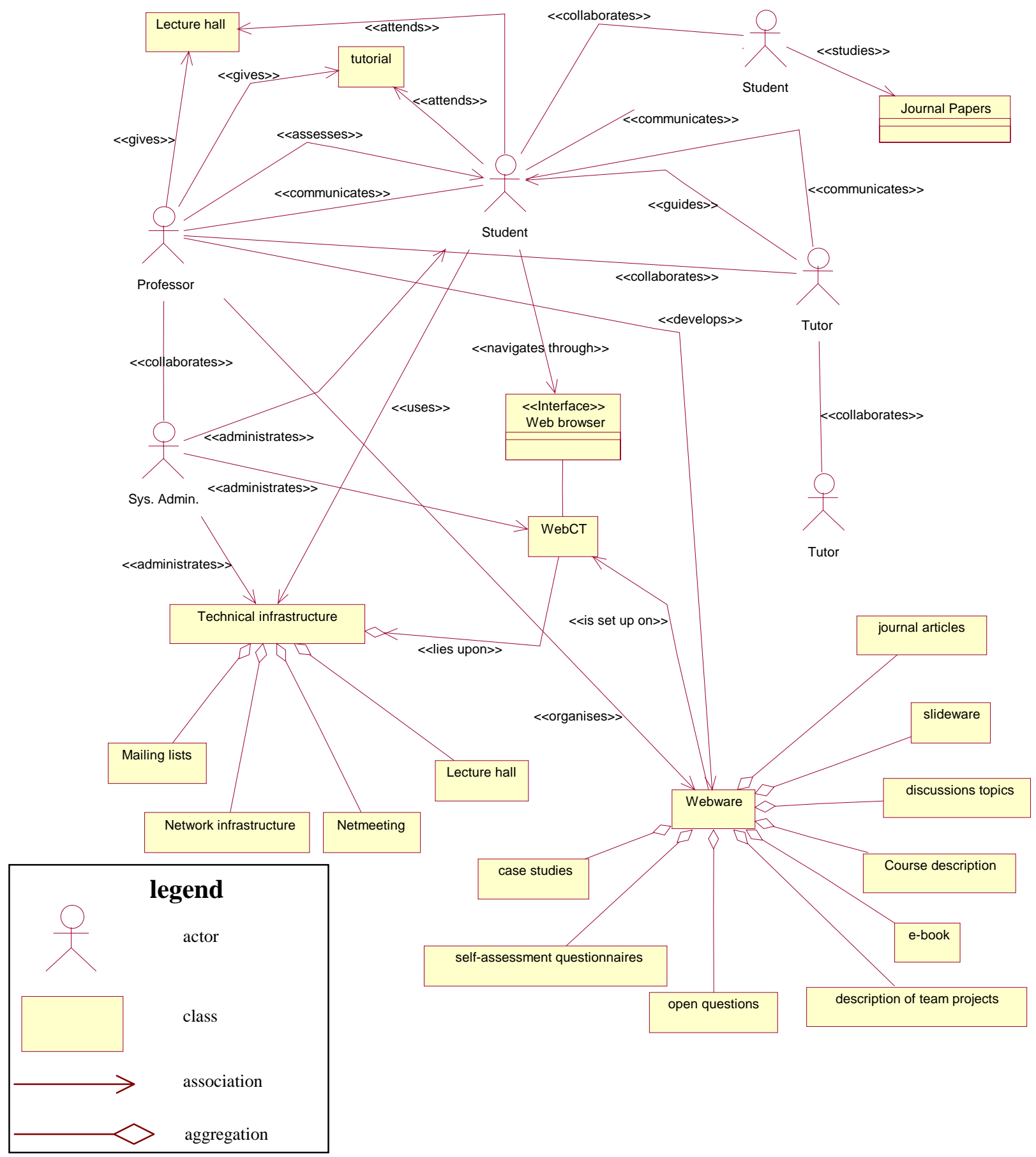

Figure 4. An object model of the course on Web Engineering. 
Out of the five refinement layers of architecture specified in the LTSA, only layer 3 (system components) is normative in this Standard. Layer 1, "Learner and Environment Interactions" addresses the learner's acquisition, transfer, exchange, formulation, discovery, etc. of knowledge and/or information through interaction with the environment. Layer 2, "Human-Centered and Pervasive Features" addresses the human aspects of learning technology systems in terms of human-specific strengths and weaknesses. Layer 3, "System Components" describes the component-based architecture, as identified in human-centered and pervasive features. Layer 4, "Stakeholder Perspectives and Priorities" describes learning technology systems from a variety of perspectives by reference to subsets of the system components layer. Layer 5, "Operational Components and Interoperability — codings, APIs, protocols" describes the generic "plug-n-play" (interoperable) components and interfaces of an information technology-based learning technology architecture, as identified in the stakeholder perspectives. The added value derived from the abstraction-implementation layers, is that the five layers represent five independent areas of technical analysis, which makes it easier to discuss each layer independently of the others.

Similar work of defining abstraction-implementation levels has recently commenced within the standardization initiative of ISO/IEC Joint Technical Committee 1 Subcommittee 36 (http://jtclsc36.org). At this effort they start at the LTSA layer 3 and move downwards the abstractionimplementation scale. They aim to define three different standards, of different abstraction levels that describe the architecture of IT-supported environments for learning, education, and training, thus adopting the LTSA abstraction-implementation notion: (1) A highly abstract, holistic view on the basis of the latest version of the IEEE P1484.1 LTSA and especially layer 3 (system components); (2) A fairly abstract, general ingredients' view that attempts to identify the "Roles" and "Expertise" exchange, encountered in LTS; (3) A slightly abstract, specific ingredients' view that will provide a repository of components, which are abstract but near to implementation (i.e. may contain technical details). In the third level, LTSs are seen as configurations of components, taken from that repository, and specific components of one or more LTS can be identified and properly defined, and interoperability and reusability issues can be discussed.

\section{Conformance to IEEE LTSC LTSA}

We consider the harmonization of our approach with the work performed in the LTSC and the SC36 to be of paramount importance, as they provide a firm and widely-adopted background. The SC36 effort is still at a very early stage, so this section mainly focuses on the harmonization with LTSA. The realisation of the proposed model into the case study presented in the previous section can claim full conformance to the high-level architecture of IEEE LTSC, Learning Technology Systems Architecture draft 6 (http://edutool.com/ltsa). The formal conformance statement would be "Conforms to IEEE 1484.1:2001 LTSA all components". It is noted though that this standard is still a working standard in draft version, so formal conformance to it is impossible, but all LTSA system component (layer 3) features conform in the implementation of the course presented in the case study section. The conformance between the proposed classroom model and the LTSA is portrayed in two different ways: Figure 5 depicts the graphical mapping between the LTSA and the architecture of the proposed WbIS model; Table 2 correlates the LTSA system components with the proposed model components. 
Figure 5 illustrates both the LTSA layer 3 (abstraction level) components and the proposed model (implementation level) components, in the sense that the LTSA is an abstract architecture of an LTS, and the proposed model can be conceptualised as an implementation of the LTSA specifically for a WbIS. It is noted that although Figure 5 looks rather odd and sketchy, it actually follows the informal notation used in the draft standard of LTSA. The arrows then connect the corresponding components from the two levels. This is performed more analytically in Table 2 where the first column contains the LTSA layer 3 components and the first row contains the proposed model components. The rest of the cells depict the mapping between these two groups of components. In specific these cells show which exact part of the proposed model components corresponds to each one of the 18 LTSA layer 3 components. When the participating component on behalf of the WbIS model, is the WebCT environment, then the specific components within WebCT are displayed, in order to provide better clarity and insight.

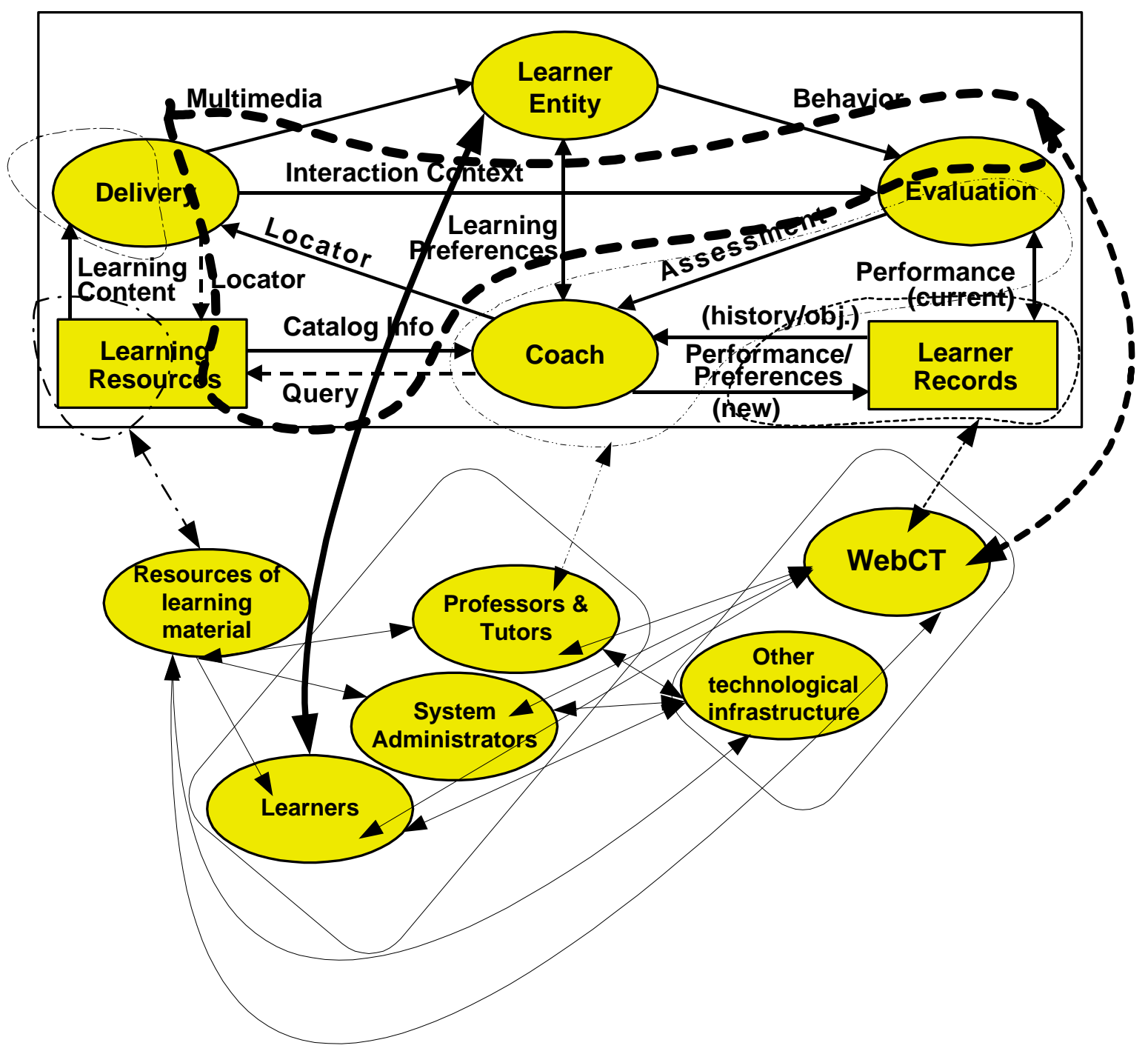

Figure 5. The mapping between the LTSA and the proposed architecture 
Retalis \& Avgeriou

\begin{tabular}{|c|c|c|c|c|}
\hline $\begin{array}{r}\text { WbIS } \\
\text { model } \\
\text { subsystems } \\
\text { LTSA component }\end{array}$ & Technical infrastructure & $\begin{array}{l}\text { Human } \\
\text { Resources }\end{array}$ & $\begin{array}{l}\text { Web-based } \\
\text { learning } \\
\text { resources }\end{array}$ & $\begin{array}{l}\text { Non web- } \\
\text { based } \\
\text { learning } \\
\text { resources }\end{array}$ \\
\hline Learner Entity & & Student & & \\
\hline $\begin{array}{l}\text { Behavior data flow from Learner } \\
\text { Entity to Assessment }\end{array}$ & $\begin{array}{c}\text { WebCT (User management, } \\
\text { Assessment, Hypermedia delivery) }\end{array}$ & & $\begin{array}{l}\text { Self-assessment } \\
\text { questionnaires, } \\
\text { exercises, open } \\
\text { questions }\end{array}$ & \\
\hline Evaluation process & $\begin{array}{c}\text { WebCT (User management, } \\
\text { Assessment) }\end{array}$ & $\begin{array}{l}\text { Professor, } \\
\text { Tutors }\end{array}$ & & \\
\hline $\begin{array}{l}\text { Assessment data flow from } \\
\text { Evaluation to Coach }\end{array}$ & $\begin{array}{c}\text { WebCT (Assessment, Hypermedia } \\
\text { delivery) }\end{array}$ & $\begin{array}{l}\text { Professor, } \\
\text { Tutors }\end{array}$ & & \\
\hline $\begin{array}{l}\text { Performance data flow between } \\
\text { Evaluation and Learner Records }\end{array}$ & $\begin{array}{l}\text { WebCT (User profile management, } \\
\text { Hypermedia delivery, Assessment) }\end{array}$ & $\begin{array}{l}\text { Professor, } \\
\text { Tutors }\end{array}$ & & \\
\hline Learner Records data store & WebCT (User Profiles management) & & & \\
\hline $\begin{array}{l}\text { Performance and Preferences } \\
\text { data flow from learner records to } \\
\text { coach }\end{array}$ & $\begin{array}{l}\text { WebCT (User profile management, } \\
\text { Hypermedia delivery, User } \\
\text { management, School Administration) }\end{array}$ & & & \\
\hline $\begin{array}{l}\text { Performance and Preferences } \\
\text { data flow from Coach to Learner } \\
\text { Records }\end{array}$ & $\begin{array}{l}\text { WebCT (User profile management, } \\
\text { Hypermedia delivery, } \\
\text { User management, User management, } \\
\text { School Administration) }\end{array}$ & & & \\
\hline $\begin{array}{l}\text { Learning Preferences between } \\
\text { Learner Entity and Coach }\end{array}$ & & $\begin{array}{l}\text { Student, } \\
\text { Professor, } \\
\text { Tutors }\end{array}$ & & \\
\hline Coach process & & $\begin{array}{l}\text { Professor, } \\
\text { Tutors, } \\
\text { Administrator }\end{array}$ & & \\
\hline $\begin{array}{l}\text { Query control flow from Coach } \\
\text { to Learning Resources }\end{array}$ & $\begin{array}{c}\text { WebCT (Searching, Course } \\
\text { Management) }\end{array}$ & & & \\
\hline Learning Resources data store & WebCT (Course management) & & $\begin{array}{l}\text { Course description, } \\
\text { e-book, articles in } \\
\text { on-line journals, } \\
\text { case studies, } \\
\text { description of team } \\
\text { projects and } \\
\text { exercises, slideware }\end{array}$ & Journal papers \\
\hline $\begin{array}{l}\text { Catalog Info data flow from } \\
\text { Learning Resources to Coach }\end{array}$ & $\begin{array}{c}\text { WebCT (Searching, Course } \\
\text { Management) }\end{array}$ & & & \\
\hline $\begin{array}{l}\text { Locator data flow from Coach to } \\
\text { Delivery }\end{array}$ & $\begin{array}{l}\text { WebCT (Hypermedia Delivery, } \\
\text { Course management) }\end{array}$ & & & \\
\hline Delivery process & $\begin{array}{l}\text { WebCT (Hypermedia Delivery, } \\
\text { Courseware Authoring, User } \\
\text { management, course management, } \\
\text { study toolkit, help desk, System } \\
\text { administration) and the rest of the } \\
\text { technological infrastructure }\end{array}$ & & & \\
\hline $\begin{array}{l}\text { Locator control flow from } \\
\text { Delivery to Learning Resources }\end{array}$ & WebCT (Hypermedia Delivery) & & & \\
\hline $\begin{array}{l}\text { Learning Content data flow from } \\
\text { Learning Resources to Delivery }\end{array}$ & WebCT (Hypermedia Delivery) & & & \\
\hline $\begin{array}{l}\text { Interaction Context data flow } \\
\text { from Delivery to Evaluation }\end{array}$ & $\begin{array}{c}\text { WebCT (Hypermedia Delivery, } \\
\text { Assessment) }\end{array}$ & & & \\
\hline
\end{tabular}

Table 2: The mapping between the LTSA components and the proposed model components 


\section{Summative Evaluation of a WbIS in Accordance with Its Model}

Summative evaluation is the collection, the analysis and the interpretation of information about any aspect of a programme of education or training as part of a recognised process of judging its effectiveness, its efficiency, and any other outcomes it may have (LTDI, 1998). It should be a planned systematic and open endeavour (Calder, 1995). It should concern the learning event at a holistic level, taking into account the context of learning and all the associated factors, aiming to make alterations, improvements, and extensions to a WbIS as a whole or to its subsystems. A WbIS can be evaluated with the aid of a viable summative evaluation method whose goal is to measure the learning effectiveness of the WbIS as well as to assess the learning impact of sub-systems in quantifiable and qualitative terms. The learning effectiveness of a WbIS can be influenced by a number of variables, such as:

- Relevance of the WbIS to the learners' body (learning expectations, preferred place and time of study, etc.);

- Effect of WbIS on students' learning styles;

- Contribution of the learning resources to the acquisition of knowledge and skills;

- Quality of the instructional support services provided by the human agents in respect to the learners' acquisition of knowledge and skills;

- Quality of the learning resources;

- Quality and usability of the technical infrastructure subsystem;

The proposed method is a pre-test and post-test summative evaluation method. It is supported by specially developed pre-test and post-test questionnaires, which provide data for both quantitative and qualitative analysis. The first kind (pre-test questionnaire) aims at identifying the expectations of the learners from the WbIS. This questionnaire is administered during the first days of the course delivery and not later than the first week. Pre-testing would be pointless if the learners are exposed to the WbIS. The second kind (post-test questionnaire) aims to deduce overall judgments and criticism on the learning effectiveness of the WbIS. The results of post-testing will vary considerably depending on how soon the test is dispensed after the learner has used the systems. It would be ideal if the test were administered immediately after the learning session.

The pre-test questionnaire is structured in two main parts, both comprised by closed-end questions, 29 in total (measured in a Likert scale). The first part concerns the learners' profile. Having data on students is important. Such data are the demographic characteristics of the learners which involve age, sex, prior study profiles, previous uses of web technology, time spent on commuting, preferred time and place of study, etc. In the post test questionnaire the learners' data is complemented by issues like the time spent on studying the subject domain, the time spent using some functionalities of the technical infrastructure (e.g. e-mail, downloading) and so on. The answers to these questions offer information about the relevance of the WbIS to the learners' body. The questions appearing in the pre-test are also replicated in the post-test in a rephrased form. However, the post-test questionnaire consists of a wide number of closed-end questions that are used to evaluate in detail specific issues on the quality of the on-line learning material, the instructional support provided by the human agents, etc. It also includes a section with a number of open-ended questions to supplement the quantitative data. The open-ended section concerns issues related to students' likes and dislikes towards the WbIS, the deficiencies concerning the WbIS subsystems, suggestions for improving the instructional support, the learning resources, and the technological infrastructure, etc.

The results from the analysis of data extracted from the questionnaires are complemented by an analysis of the assessment results of the students that participate to the specific course. In addition, an analysis of the statistics of usage of the functionalities entailed in the technological infrastructure of the WbIS (i.e. 
number of e-mails exchanged, access rates to learning resources, etc.) is being made so as to draw a more complete picture of the impact of the system to the learning process. Details about the evaluation method and the evaluation study for the course on "Web Engineering" can be found in (Retalis et al. 2001).

In summary, the total number of postgraduate students who responded to the evaluation study reached up to 16 ( 2 women and 14 men). In terms of the time spent accessing the web-based learning environment, the majority of the students spent approximately 1-2 hours per week. Finally, none of them had any problem in reading material suggested in bibliography that was written in English. The analysis of the data showed that students found the WbIS easy, intuitive to use and efficient, as it provided a flexible environment and allowed them to work at their own pace, time and place. It has also been consistently indicated that due to the potential for periodic extension and update of the material in learning resources, the WbIS provided great flexibility for meeting identified educational needs and a variety in learning styles. Students also felt that the learning resources involved high interactivity, was aesthetically pleasing, challenged them with simulations and referenced material. In general, the WbIS avoided making students simply absorb the knowledge but offered opportunities for practice and active involvement.

The likes and dislikes derived from the qualitative analysis of the data, which were gathered during a summative evaluation process of the first version of this WbIS, are mentioned below:

\section{Likes}

- Easy acquisition of information related to the course.

- Lack of restrictions in time and place in terms of communication with the tutors and studying of the learning material.

- Selective collection of the learning material for downloading or printing.

- Usability of the learning material.

- The existence of case studies.

\section{Dislikes}

- The elaborated case studies on the hypermedia development methodologies were limited.

- There were not many subjects for discussions.

- Some answers to students' queries were given personally without update to the discussion list.

As already mentioned the new version of this WbIS differs from the first version based on the feedback given from the students.

\section{Conclusions and Future Work}

The design, construction and maintenance of web-based instructional systems are not easy tasks. People wishing to develop such systems need models and processes that aid their job in a well-defined and standardised way. Our future plans primarily include the application of the proposed model into a variety of web-based instructional systems. Such an attempt has already started with the systematic design and development of tele-training courses in the bank sector.

Moreover, the new research steps will be towards the use of design patterns that will complement the proposed WbIS model. Design patterns are a good means for recording design experience as they systematically name, explain and evaluate important and recurrent designs in software systems (Gamma et al., 1995). They describe problems that occur repeatedly, and describe the core of the solution to these 
problems, in such a way that we can use this solution many times in different contexts and applications. Looking at known uses of a particular pattern, we can see how successful designers solve recurrent problems. In some cases, it is possible to give structure to simple patterns to develop a pattern language: a partially ordered set of related patterns that work together in the context of certain application domain. This work will be in line with the research efforts that are being performed by (Rossi, et al., 1999), (Garzoto et al., 1999), (Lyardet 1998) and (Bichler 1997).

Finally some enhancements to the WbIS model are being planned and these include: an architecting process, that can guide the instructional design team step-by-step into designing and implementing the WbIS model; the evolution of the WbIS model into an application framework, i.e. a generic WbIS that an instructional design team can tailor to fit the needs of a specific instructional problem. Both of these enhancements are intended to focus on the information technology perspective of WbISs, and not represent current theories of learning, just like the proposed model.

\section{References}

Bichler, M. \& Nusser, S (1997). Modular Design of Complex Web-Applications with SHDT. In http://dec9.wuWien.ac.at/w3dt/wetice/wetice.htm

Calder, J. (1995), Programme Evaluation and Quality: A Comprehensive Guide to Setting up an Evaluation System, Institute of Educational Technology, Open University, Kogan Page.

Carlson, P. A. (1998). Advanced Educational Technologies - Promise and Puzzlement, Journal of Universal Computer Science (JUCS), (Special Issue), 4(3).

Ford, P., Goodyear, P., Heseltine, R., Lewis, R., Darby, J., Graves, J., Sartorius, P., Harwood, D. \& King. T. (1996). Managing Change in Higher Education: A Learning Environment Architecture, London: Open University Press.

Gagné, R., Briggs, L. \& Wager, L. (1994) Principles of Instructional Design, Fort Worth, TX: HBJ College Publishers.

Gamma, R. Helm, R. Johnson \& Vlissides, J. (1995). Design Patterns: elements of reusable object-oriented software, Addison Wesley.

Garzoto, F., Paolini P., Bolchini D., \& Valenti S. (1999). Modeling-by-patterns of web applications, Lecture Notes in Computer Science, 1727, Springer.

Hodgson, V. (1997). New technologies and learning: Accepting the challenge, Management Learning, J. Burgoyne \& M. Reynolds (eds.), SAGE Publications, London.

Humphrey, W. S. (1995). A Discipline for Software Engineering, Addison-Wesley.

IEEE Learning Technology Standards Committee: Draft Standard for Learning Technology Systems Architecture (LTSA). Draft 8, April 2001.

Isakowitz, E., Stohr, A., \& Balasubramanian, P. (1995), "RMM: A Methodology for Structured Hypermedia Design", Communications of the ACM, Vol. 35 (8), August 1995.

Learning Technology Dissemination Initiative (1998), Evaluation Cookbook, ISBN 0952873168, (http://www.icbl.hw.ac.uk/ltdi/cookbook

Lowe, D. and Hall, W. (1999). Hypermedia \& the Web: An Engineering Approach, John Wiley Ltd.

Lindner, R. (tech. ed.) (2001). Expertise and Role Identification for Learning Environments (ERILE), Proposed Standard Draft for German DIN NI-36 (planned to be a mirror for the ISO/IEC JTC1 SC36), (http://WwW.1gd.thg.de/ lindner/PRUMETEUS/STG-DESTGN_Vleeting-Point.htm)

Lyardet, F., Rossi G., \& Schwabe, D. (1998). Patterns for Dynamic Websites, Proceedings of PloP'98, Allerton, USA.

McConnell, D. (1994). Implementing computer-supported cooperative learning, London: Kogan Page.

McCormack, C. \& Jones, J. D. (1997). Building a Web-based Education System, Wiley Computer Publishing.

Moore, M. G., \& Kearsley, G. (1996). Distance Education: A Systems View, Wadsworth Publishing Company.

Retalis, S., Psaromiligkos, Y., \& Avgeriou, P., (2001). Web Engineering: New Discipline, New Educational Challenges, Information Services \& Use, ISSN 0167-5265 (forthcoming) 
Rossi, G., Schwabe, D. \& Lyardet, F. (1999). Improving Web information systems with Navigational patterns, International Journal of Computer Networks and Applications, May 1999.

Schash, S. R. (1990). Chapter 3: Software Life Cycle Models, Software Engineering, pp. 20-40, Homewood, IL: Aksen Associates.

Spector, J. M., \& Song, D. (1995). Automated Instructional Design Advising, Automating Instructional Design: ComputerBased Development and Delivery Tools, R. D. Tennyson \& A. E. Barron (eds), Berlin: Springer-Verlag.

Schwabe, D., \& Rossi, G. (1995), "The Object-Oriented Hypermedia Design Model (OOHDM)", Communications of the ACM, Vol. 35 (8), August 1995.

Tennyson, R. D. \& Breuer. K. (1997). Instructional theory: Psychological perspectives. In R. D. Tennyson, F. Schott, N. Seel, and S. Dijkstra (Eds.), Instructional design: International perspectives, Vol. I: Theory and research, Hillsdale, NJ: Erlbaum.

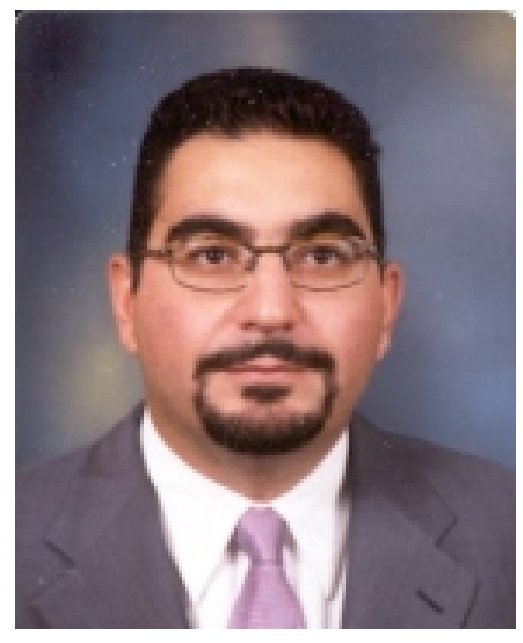

\section{Biographies}

Dr. Symeon Retalis is Lecturer at the Department of Computer Science, University of Cyprus. He holds a diploma of Electrical and Computer Engineer from the Department of Electrical and Computer Engineering studies, National Technical University of Athens, Greece. His MSc degree is on the Information Technology-Knowledge Based Systems from the Department of Artificial Intelligence, University of Edinburgh, Scotland. In 1998 he was awarded with a PhD from the Department of Electrical and Computer Engineering, National Technical University of Athens, Greece. His research interests lie on the web-based courseware development, hypermedia systems design, and web engineering. He serves in the editorial board of international journals and participates to the ACM Web Engineering special interest group and to the IEEE Learning Technologies Standardisation Committee.

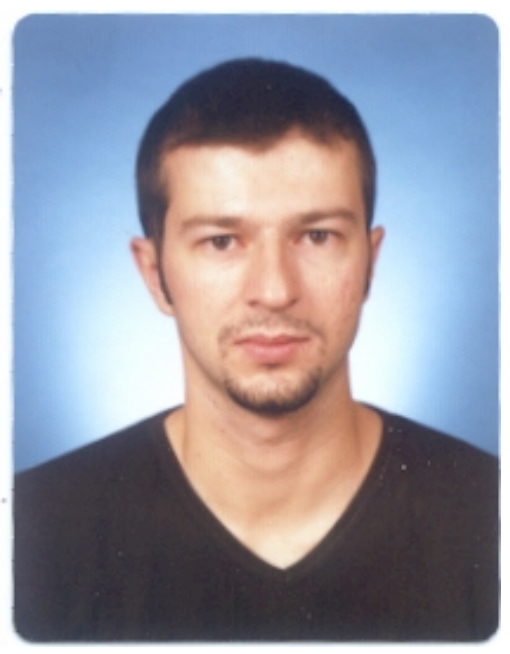

Paris C. Avgeriou received his diploma in Electrical and Computer Engineering from the National Technical University of Athens (NTUA). After graduating (1999), he joined the Software Engineering Laboratory research team of the NTUA as a Ph.D. candidate, and has received several academic awards and scholarships since then. He is working as a researcher in national and EU projects and has published several papers in international conferences and journals. He acts as a reviewer in journals and conferences and takes part in EU and international standardization activities. His research interests lie in the intersection of Advanced Learning Technologies and Software and Hypermedia Engineering. 